https://doi.org/10.22210/suvlin.2018.086.11

\title{
Kristian Lewis (2016). Lažni prijatelji s Rječnikom hrvatsko-ruskih lažnih prijatelja. Zagreb: Institut za hrvatski jezik i jezikoslovlje, 441 str.
}

Godine 2016. Institut za hrvatski jezik i jezikoslovlje objavio je knjigu dr. sc. Kristiana Lewisa Lažni prijatelji s Rječnikom hrvatsko-ruskih lažnih prijatelja. Knjiga je dio biblioteke Prinosi hrvatskomu jezikoslovlju.

U Predgovoru autor navodi da je knjiga prerađeni i dopunjeni tekst njegova doktorskoga rada Hrvatsko-ruski lažni prijatelji obranjenoga 2010. godine na Filozofskome fakultetu Sveučilišta u Zagrebu.

Knjiga ima ukupno 441 stranicu i podijeljena je na 14 dijelova.

Nakon Uvoda (str. 1-4) slijedi poglavlje Metodologija istraživanja lažnih prijatelja (str. 5-22) koje se sastoji iz triju potpoglavlja. Metodološki okvir istraživanja prati znanstvene spoznaje dviju temeljnih lingvističkih grana - genetske lingvistike i kontaktne lingvistike - u okviru kojih se najčešće proučavaju lažni prijatelji. Tim je dvjema granama pridodana i traduktološka jer se upravo teorija prevođenja često bavi problemom lažnih prijatelja. Potpoglavlje Genetskolingvističke postavke donosi osnovne genetskolingvističke značajke hrvatskoga i ruskoga jezika te se utvrđuju pretpostavke za mogućnost istraživanja lažnih prijatelja. Potpoglavlje Kontaktološke postavke ukratko predstavlja relevantne kontaktologe i prikazuje rezultate dosadašnjih hrvatsko-ruskih kontaktoloških istraživanja. U poglavlju Traduktološke postavke daje se pregled traduktoloških teorija i načela, razmatra odnos traduktologije i lingvistike te književne teorije.

Treće se poglavlje, Nazivoslovno određenje lažnih prijatelja (str. 23-32), sastoji od dvaju potpoglavlja. U prvome, Predloženi nazivi injihova podjela, popisani su, grupirani i komentirani termini za lažne prijatelje u trinaest svjetskih jezika. K. Lewis razvrstava brojne nazive u tri skupine: nazivi s nejezikoslovnim sastavnicama (npr. lažni prijatelji), nazivi s već ustaljenim, ali sad proširenim lingvističkim značenjem (npr. homonim) te novi nazivi (npr. tautonim). U potpoglavlju Nazivoslovna načela i izbor operativnoga naziva prikazana su terminološka načela prema kojima se predlaže operativni naziv lažni prijatelji upotrijebljen u knjizi.

Četvrtoje poglavlje, Tipologije lažnih prijatelja (str. 33-52), posvećeno pregledu tipologija lažnih prijatelja u različitim svjetskim jezicima. Pritom su u obzir uzeti znanstveni radovi iz područja lingvistike, teorije prevođenja te rječnici lažnih prijatelja.

U poglavlju Leksikografska obrada lažnih prijatelja (str. 53-70) prikazani su pristupi leksikografskoj obradi lažnih prijatelja u dvojezičnoj i višejezičnoj leksikografiji. Opisani su i komentirani dvojezični rječnici srodnih jezika, rječnici jezika koji nisu genetski bliski te Peterojezični rječnikeuropeizama.

U šestome je poglavlju, Korpus hrvatsko-ruskih lažnih prijatelja (str. 71-106), opisan način prikupljanja građe za istraživanje te osnovna obilježja same građe. Korpus lažnih prijatelja obuhvaća 864 hrvatska leksema i 1.086 ruskih leksema. U trećemu se potpoglavlju, Raslojenost leksika u korpusu, analizira raslojenost leksi- 
ka na sljedećih pet razina: vremenska, područna, stilska, prijenos značenja i nazivoslovna. U dijelu Vremenska raslojenost razmatraju se hrvatski leksemi obilježeni odrednicama arh., pov. i zast. (npr. gnus, aparatčik, gvozd) te ruski leksemi obilježeni odrednicama ист. i yстар. (npr. невольник, яство). Ukupno je vremenski markirano 29 hrvatskih i 46 ruskih leksema. U dijelu Područna raslojenost utvrđuje se da se na hrvatskoj strani korpusa nalazi jedna odrednica - reg., kojom je obilježeno 14 leksema (npr. plac), dok na ruskoj strani takva odrednica izostaje. U dijelu Stilska raslojenost govori se o stilskim nijansama i različitim funkcionalnim stilovima zastupljenima u korpusu. Na hrvatskoj strani korpusa nađene su odrednice pogr., razg. i žarg. (npr. armada, pokaz, familija), dok su na ruskoj strani korpusa potvrđene 23 odrednice, razvrstane u tri veće skupine: a) книжн., офиц., публиц., трад.-поэт., нар.-поэт. і спеи. (npr. фамилия, наличие, столица, кров, красный, палеи); b) разг., разг.-сниж., трад.-нар., нар.-разг., проф. іжарг.(nрr. академик, чурка, бранить, крупица, зарез, штука) tе с) высок., сниж., ласк., шутл., неодобр., ирон., пренебр., презрит., бранно., грубо. і вульг. (npr. година, подвести, чайник, пилить, шишка, лепет, тварь, гнус, орать, засрать). Ukupno je stilski obilježeno 36 hrvatskih leksema te 533 ruska leksema. U potpoglavlju Prijenos značenja utvrđeno je da se odrednica pren. nalazi samo u hrvatskome dijelu korpusa, a njome je obilježeno 90 hrvatskih leksema (npr. cvijet). U potpoglavlju Nazivoslovna raslojenost razmotreni su leksemi obaju jezika obilježeni strukovnim odrednicama. Na hrvatskoj strani korpusa potvrđene su 64 strukovne odrednice (npr. adm. nalog, film. bunker), a na ruskoj - 30 (npr. воен. колонна, муз. вокал). Na hrvatskoj su strani korpusa 373 leksema obilježena kao termin, a na ruskoj-88.

U poglavlju Analiza korpusa hrvatsko-ruskih lažnih prijatelja (str. 107-184) utvrđena su dva polazna kriterija analize - izrazni i sadržajni, a rezultat analize jest klasifikacija korpusnih leksema. Potpoglavlje Analiza korpusa prema izraznome kriteriju obuhvaća Grafijsku analizu, u kojoj se razmatra odnos grafema i fonema u hrvatskome i ruskome jeziku. U potpoglavlju Fonološka analiza oprimjeruje se dokidanje distinkcije između ruskih palataliziranih i nepalataliziranih fonema u hrvatskome te ostali odnosi navedeni u Grafijskoj analizi, samo sada s fonološkoga aspekta. Analizira se i naglasak u hrvatskome i ruskome, refleks jata, punoglasje, jednačenje po zvučnosti te odnosi suglasničkih skupina $-s t-/-c m H-i-s ̌ t-/-u m-$. U potpoglavlju Morfološka analiza navode se promjenljive i nepromjenljive vrste riječi obuhvaćene korpusom hrvatsko-ruskih lažnih prijatelja. Od promjenljivih vrsta riječi zastupljene su imenice, glagoli i pridjevi, a od nepromjenljivih veznici, prijedlozi i čestice. U potpoglavlju Imenice podrobnije je istražena gramatička kategorija roda imenica, a u suodnos su dovedeni i sufiksi-ac -eu, -je -ue, -nje -нuе i-nje $\sim-$ - be. U potpoglavlju Glagoli uspoređeni su infinitivni sufiksi u hrvatskome (-ti, -ći) s onima u ruskome $(-m b,-u b,-m u)$ te su navedene razlike koje su uočene s obzirom na gramatičku kategoriju glagolskoga vida. Analizirana je i kategorija povratnosti te su izdvojeni korpusni primjeri tzv. neuzajamne povratnosti (neki su glagoli u hrvatskome povratni, a u ruskome nisu i obratno). Provedena je i analiza glagola 
s različitim vidom, pri čemu su posebno razmotrena značenja glagolskih prefiksa kojima se mijenja kategorija vida (prefiksi iz-, s-, u-, za-). Zaključeno je da postoje značenja jednakih prefikasa u ruskome i hrvatskome jeziku koja su podudarna, kao i da postoje značenja jednakih prefikasa u ruskome i hrvatskome jeziku koja su nepodudarna pa ta činjenica dodatno usložnjava problem lažnih prijatelja. U potpoglavlju Pridjevi uspoređeni su hrvatski određeni i neodređeni oblici pridjeva te ruski dugi i kratki pridjevi. Suodnos je uspostavljen između hrvatskoga nastavka -i i triju ruskih nastavaka - bı̆, -uй i-oŭ. U potpoglavlju Nepromjenljive riječi zastupljene su tri skupine nepromjenljivih riječi - veznici, prijedlozi i čestice, dok prilozi i uzvici nisu potvrđeni.

U drugome potpoglavlju, Analiza korpusa prema sadržajnome kriteriju, težište je stavljeno na uočavanje, usporedbu i tumačenje korelacija među značenjima leksema hrvatskoga i ruskoga jezika koji tvore par ili parove lažnih prijatelja. Analizom prema sadržajnome kriteriju utvrđeno je da je suodnosima leksema tih dvaju jezika nastalo 745 parova potpunih lažnih prijatelja (71,5 \%) i 297 parova djelomičnih lažnih prijatelja (28,5 \%). Ukupno je riječ o 1.042 para lažnih prijatelja. Posebno su analizirani internacionalizmi u korpusu, ukupno 20 skupina u obama jezicima, te je potvrđena već iznesena pretpostavka da etimologija nema važnu ulogu u uspostavi parova lažnih prijatelja jer refleksno prepoznavanje i pogrešno zaključivanje o značenju inojezičnoga leksema ne ovisi o njoj, nego o iskustvu sudionika u komunikaciji, koje se temelji na spoznajama polaznoga jezika. Navedeni su i primjeri pejorizacije značenja i kod potpunih i kod djelomičnih lažnih prijatelja, a analizom je utvrđeno da to uglavnom podrazumijeva i suženje značenja. U potpoglavlju Potpuni lažni prijatelji analizirani su primjeri potpunih lažnih prijatelja koji dijele semantičko polje, ali je u dvama jezicima došlo do segmentacije značenjske periferije, a zatim i parovi lažnih prijatelja koji imaju posve oprečna značenja od onih koje govornici pojedinoga jezika očekuju te naposljetku parovi potpunih lažnih prijatelja s oprekom »živo« "neživo«. Na kraju te analize donosi se cjelovit popis parova leksema koji su potpuni hrvatsko-ruski lažni prijatelji. U potpoglavlju Djelomični lažni prijatelji analiziraju se parovi leksema s djelomičnim preklapanjem značenja, a s obzirom na to u kojem se opsegu značenja hrvatskoga i ruskoga leksema razlikuju, moguća su tri odnosa: 1. u hrvatskome postoje značenja kojih nema u ruskome, tj. hrvatski leksem ima više značenja nego ruski; 2. u ruskome postoje značenja kojih nema u hrvatskome, tj. ruski leksem ima više značenja nego hrvatski; 3 . i u hrvatskome i u ruskome postoje značenja kojih nema u drugome jeziku, tj. i hrvatski i ruski leksemi imaju značenja kojih nema u njihovu parnjaku. Na kraju analize donosi se cjelovit popis parova leksema koji su djelomični hrvatsko-ruski lažni prijatelji.

U osmome poglavlju, Leksikografske postavke Rječnika hrvatsko-ruskih lažnih prijatelja (str. 185-190), K. Lewis donosi načela ustroja Rječnika hrvatsko-ruskih lažnih prijatelja, a nakon toga slijedi sam Rječnik (deveto poglavlje, str. 191-413), u kojem se donose leksikografski obrađeni lažni prijatelji. Prikazani su dvostupačno tako da se paralelno mogu pratiti leksemi obaju jezika. Rječnički članak sadržava natuknicu s etimološkim podatkom (na mjestima gdje je to potrebno), daju se 
osnovne gramatičke i stilske odrednice te naznaka radi li se o potpunome ili djelomičnome lažnom prijatelju (kratice P i D). Dalje slijedi značenje ili niz značenja (za hrvatsku stranu na hrvatskome jeziku, a za rusku - na ruskome) koji su ispisani iz jednojezičnih rječnika hrvatskoga, odnosno ruskoga jezika.

Navodimo četiri rječnička članka.

\begin{tabular}{|c|c|}
\hline $\begin{array}{r}\text { čoporni pridj. } \\
<\mathrm{P}> \\
\text { koji se odnosi na čopor }\end{array}$ & $\begin{array}{l}\text { чопорный } п р и л . ~ \\
\text { чрезмерно строгий, чинный в поведении, } \\
\text { в соблюдении приличий }\end{array}$ \\
\hline $\begin{array}{r}\text { djevaž } \\
\langle\mathrm{D}> \\
\text { umilj. od djevojka }\end{array}$ & 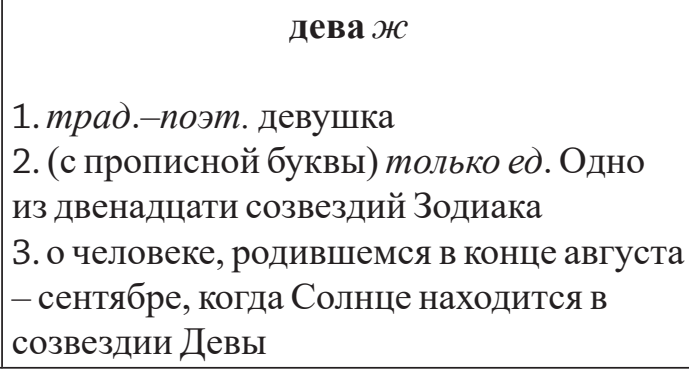 \\
\hline $\begin{array}{l}\qquad \text { istočiti } s v r . \\
\qquad \text { Р источить¹; источить }{ }^{2}> \\
\text { 1. prel. učiniti da istekne, iscuri; } \\
\text { izliti } \\
\text { 2. neprel. isprazniti se točeći; iscu- } \\
\text { riti, izliti se }\end{array}$ & $\begin{array}{l}\text { 1. многократным точением истереть, } \\
\text { сделать тоныше } \\
\text { 2. = изъесть (испортить, повредить, грызя } \\
\text { или подтачивая (о насекомых) } \\
\text { источить } 2 \text { св. } \\
\text { 1. книжн. издать, испустить, } \\
\text { распространить (свет, запах и т.п.) } \\
\text { 2. высок. выделить из себя какую-л. влагу }\end{array}$ \\
\hline $\begin{array}{l}\qquad \begin{array}{l}\text { da1 veznik } \\
\qquad\langle\mathrm{P}\rangle\end{array} \\
\text { 1. izriče namjeru radnje glavne re- } \\
\text { čenice, namjerni veznik; kako bi, } \\
\text { ne bi li (Trčala je da stigne.; Otišli su } \\
\text { u šumu da naberu gljiva.) } \\
\text { 2. iskazuje posljedicu radnje glav- } \\
\text { ne rečenice, posljedični veznik; } \\
\text { te, pa (Spustili se oblaci da se nije } \\
\text { ništa vidjelo.; Biloje teško da smo } \\
\text { posustali.) }\end{array}$ & $\begin{array}{l}\text { 1. (соединяет однородные чл. предл., } \\
\text { повторяшчиеся сл. и предл.) = И (Хороший } \\
\text { да пригожий.; Хлеб да соль вам!) } \\
\text { 2. (присоединяет предл. и чл. предл.) } \\
\text { указывает на развитие, дополнение, } \\
\text { пояснение высказанной мысли или } \\
\text { характеристику, оценку сказанного } \\
\text { (Обидели, да ещё как!; Такая женшчина } \\
\text { плачет, да притом по пустякам.) }\end{array}$ \\
\hline
\end{tabular}




\begin{tabular}{|c|c|}
\hline $\begin{array}{l}\text { 3. izriče uvjet koji nije ispunjen ili } \\
\text { se ne može ispuniti za ostvarenje } \\
\text { pogodbe, pogodbeni veznik; kad } \\
\text { bi (Kupila bih haljinu da imam no- } \\
\text { vaca.; Da si javio, došla bih.) } \\
\text { 4. izriče pomišljeni uvjet, a ne i } \\
\text { zbiljski ispunjen, dopusni veznik; } \\
\text { makar, premda, iako (Ne mogu dai } \\
\text { hoću.; Otići ću pa da me i ubiju.) } \\
\text { 5. izriče pobliže tumačenje glavne } \\
\text { rečenice, izrični veznik; kako, gdje } \\
\text { (Rekla mi je da sam dobra.; Vidim da } \\
\text { radi.) } \\
\text { 6. izriče uzročni odnos glavne i za- } \\
\text { visne rečenice, uzročni veznik; jer, } \\
\text { zbog toga što, stoga što, što (Sme- } \\
\text { ta ga da mu nisu rekli.; Zahvaljujući } \\
\text { tomu da je bio dobre volje, sveje } \\
\text { dobro prošlo.) } \\
\text { 7.izriče vremenski odnos glavne } \\
\text { i zavisne rečenice, vremenski ve- } \\
\text { znik; kako, otkako (Ima više godina } \\
\text { da se nismo vidjeli.) } \\
\text { 8. izriče pridruživanje glavnoj } \\
\text { rečenici, odnosni veznik; koji, tko } \\
\text { (Nema nikoga da želi raditi.) } \\
\text { 9. služi za pretvaranje upravnoga } \\
\text { govora u neupravni (Rekaoje da ga } \\
\text { nečekamo.) } \\
\text { 10. u sprezi sjer služi za navođenje } \\
\text { tuđih riječi izričući i sumnju u isti- } \\
\text { nitost navoda; navodno (Nije došla } \\
\text { jer da nije stigla na vlak.) }\end{array}$ & $\begin{array}{l}\text { 3. (присоединяет предл. и чл. предл.) } \\
\text { употр. при перечислении однородных } \\
\text { членов предложения и предложений (A } \\
\text { было на нём без малого пуд: рюкзак со } \\
\text { снаряжением, да палатка, да льљжи.) } \\
\text { 4. (присоединяет предл. и чл. предл.) } \\
\text { выражает противопоставление, } \\
\text { несоответствие или ограничение } \\
\text { предшествующего; но, однако (Светит, } \\
\text { да не греет.; Они меня не знают, да я-mо } \\
\text { иххорошо знаю!) }\end{array}$ \\
\hline
\end{tabular}

Nakon Rječnika u knjigu su uključeni sljedeći dijelovi: 10. Zaključak, str. 415420; 11. Literatura, str. 421-437; 12. Sažetak, str. 439; 13. Резюме, str. 440; 14. Abstract, str. 441.

U Zaključku se dosta opširno iznose osnovne teorijske postavke iz istraživanja lažnih prijatelja. U dijelu Literatura navodi se popis od oko 235 bibliografskih jedinica, što dokazuje da je K. Lewis upoznat s recentnom literaturom koja obrađuje temu lažnih prijatelja, pri čemu prema dijelu stavova iznesenih u radovima iznosi 
argumentirano neslaganje, ali, što je važnije, njegovo istraživanje donosi nove podatke i zaključke o temi lažnih prijatelja.

Knjiga bi se, uvjetno rečeno, mogla podijeliti na teorijski i na leksikografski dio. Što se teorijskoga dijela tiče, možemo konstatirati da je to najopsežniji, metodološki najpotpuniji i teorijski najtemeljitiji rad o toj temi u Hrvatskoj. Teorijski dio rezultira dosad najvećim popisom i leksikografskim opisom hrvatsko-ruskih lažnih prijatelja. Rječnik hrvatsko-ruskih lažnih prijatelja smatramo vrlo bitnim dijelom knjige koji ima veliku praktičnu vrijednost.

Knjiga Kristiana Lewisa Lažni prijatelji s Rječnikom hrvatsko-ruskih lažnih prijatelja namijenjena je u prvome redu kroatistima i rusistima koji se bave različitim aspektima kontaktne lingvistike i traduktologije, ali ona će, uvjereni smo, zainteresirati i druge slaviste. Svakako treba naglasiti da će se njome služiti studenti kroatistike i rusistike koji pokazuju zanimanje za leksikološke teme, ali ona može biti i vrlo koristan priručnik na nastavi iz mnogih kolegija u okviru studija rusistike.

Izuzetno bitnim smatramo i činjenicu da se knjiga Lažni prijatelji s Rječnikom hrvatsko-ruskih lažnih prijatelja izvrsno uklapa u niz monografija u kojima se obrađuje navedena tema i rječnika lažnih prijatelja objavljenih u europskoj slavistici.

Željka Fink 